\title{
Back from the brink - a note of thanks
}

\author{
Daniel A Peters MD MBA FRCSC ${ }^{1}$, Douglas R McKay MD MBA FRCSC ${ }^{2}$, Edward W Buchel MD FACS, Editor-in-Chief ${ }^{3}$
}

\begin{abstract}
The tipping point is that magic moment when an idea, trend, or social behavior crosses a threshold, tips, and spreads like wildfire Malcolm Gladwell, The Tipping Point: How Little Things Can Make a Big Difference
\end{abstract}

$\mathrm{T}$ wo years ago, plastic surgery faced an existential threat. The Royal College of Physicians and Surgeons of Canada instituted a new program designed to certify subspecialties. This diploma program sought to codify standards for subspecialists and, thus, impart legitimacy to training beyond Fellowship. Fellows of the Royal College are now able to enrol in diploma programs subsequent to residency training. Graduates of these programs will be certified as Diplomats of the Royal College of Physicians and Surgeons of Canada and will be able to use that suffix in their correspondence.

Many programs applied to the Royal College for diploma certification. Among those applicants was a group of ophthalmologists who sought subspecialist certification in oculoplastic surgery. This group was formidable. They presented an argument that oculoplastic surgery has a longstanding tradition, has a defined scope of practice and is a recognized field of ophthalmology. These represented compelling arguments. However, this represented the first time in which a Royal College certification of one program would incorporate the name of another well-recognized specialty.

Plastic surgery was standing on a precipice. Other potential suitors for our name were anxiously waiting for the Royal College to decide whether the name 'Plastic Surgery' could be adopted. Surely an affirmative decision in favour of a the new oculoplastic diploma would represent an opportunity for 'facial plastic surgeons', 'oncoplastic surgeons' and 'dermatologic plastic surgeons'. In short, leaders in our field understood that certification of oculoplastic surgery would irrevocably undermine the value that our current training confers.

This had the potential to be a tipping point. Plastic surgery could remain a strong vibrant specialty, ensconced in our current traditions and rigorous standards, or it could be eroded by any specialty seeking to capitalize on decades of reputational excellence.

The Royal College sought consultation from anyone who had an interest in this decision. The Canadian Society of Plastic Surgeons responded vigorously on our behalf. Richard Warren, the Chair of the Specialty Committee in Plastic Surgery, led a formidable team to preserve the value of our name. Past Presidents of our society, including Donald Lalonde, Doug Ross and Patricia Bortoluzzi, joined the effort. Our current President, Bryan Callaghan, took up the cause enthusiastically. Members too numerous to mention also supported the process as part of a comprehensive defense.

The Royal College has a rigorous process for adjudicating such matters. They include written submissions, oral arguments and appeals. The process endured by our representatives was onerous. Multiple trips to the Royal College of Physicians and Surgeons were required, and written submissions were made to multiple arbitration panels and officials. Throughout, our advocates argued that plastic surgery has a unique tradition and body of knowledge. The value of our specialty was not confined to anatomy or physiology. Rather, that value was contained in our name. This name evokes notions of excellence and innovation. In short, they argued that our name required a vigorous defense.

Richard Warren championed the process and spent hundreds of hours preparing submissions, formulating arguments and preparing rebuttals. Each member of his team similarly acted without compensation and without self interest; their sole motivation was the protection of our designation from incursion by other disciplines.

On December 18, 2013 the Royal College of Physicians and Surgeons reached a final decision to deny the application of oculoplastic surgery for diploma certification.

This is a milestone in our specialty. The decision emphasized that the use of our name would result in irrevocable harm to our specialty. This affirmative decision represents a hope for young plastic surgeons and trainees to be able to continue our traditions of providing excellence in clinical care, research and innovation without fear of incursion from other fields. While we must continue to guard our collective reputation as our most precious commodity, the Canadian Society of Plastic Surgeons, Dr Warren and his team served as the vanguard in this initiative.

As editors of Plastic Surgery, we would like to thank the Society and this team for their time, effort and dedication to this process. We thank them for pulling our specialty back from the precipice and continuing to ensure our reputation. This may have represented a tipping point and, for now, the point has tipped in our favour.

\footnotetext{
${ }^{1}$ University of Ottawa, Ottawa; ${ }^{2}$ Queeen's University, Kingston, Ontario; ${ }^{3}$ University of Winnipeg, Winnipeg, Manitoba Correspondence: Dr Daniel A Peters, University of Ottawa, PO Box 2013, 1053 Carling Avenue, Ottawa, Ontario K1Y 4E9.

Telephone 613-795-5555, fax 613-761-4025, e-mail dannypeters1@gmail.com
} 